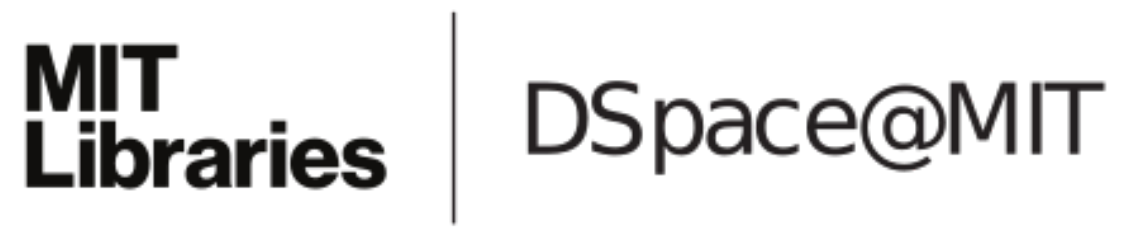

MIT Open Access Articles

A low cost high flux solar simulator

The MIT Faculty has made this article openly available. Please share how this access benefits you. Your story matters.

Citation: Codd, Daniel S. et al. "A Low Cost High Flux Solar Simulator." Solar Energy 84.12 (2010) : 2202-2212.

As Published: http://dx.doi.org/10.1016/j.solener.2010.08.007

Publisher: Elsevier

Persistent URL: http://hdl.handle.net/1721.1/65341

Version: Author's final manuscript: final author's manuscript post peer review, without publisher's formatting or copy editing

Terms of use: Creative Commons Attribution-Noncommercial-Share Alike 3.0 


\section{A Low Cost High Flux Solar Simulator}

Daniel Codd*,codd@mit.edu

Andrew Carlson, acarlson@mit.edu

Jennifer Rees, jrees@mit.edu

Alexander Slocum, slocum@mit.edu

Department of Mechanical Engineering,

Massachusetts Institute of Technology,

77 Massachusetts Avenue,

Cambridge, MA 02139

Phone: (617) 253-1953

Fax: (617) 258-6427

*corresponding author

\section{Abstract:}

A low cost, high flux, large area solar simulator has been designed, built and characterized for the purpose of studying optical melting and light absorption behavior of molten salts. Seven $1500 \mathrm{~W}$ metal halide outdoor stadium lights are used as the light source to simulate concentrating solar power (CSP) heliostat output. Metal halide bulbs and ballasts are far less costly per-watt than typical xenon arc lamp solar simulator light sources. They provide a satisfactory match to natural sunlight; although 'unfiltered' metal halide lights have irradiance peaks between 800 $1000 \mathrm{~nm}$ representing an additional $5 \%$ of measured energy output as compared to terrestrial solar irradiance over the same range. With the use of a secondary conical concentrator, output fluxes of approximately $60 \mathrm{~kW} / \mathrm{m}^{2}(60$ | suns) peak and $45 \mathrm{~kW} / \mathrm{m}^{2}$ (45 suns) average are achieved across a $38 \mathrm{~cm}$ diameter output aperture. Unique to the design of this simulator, the tilt angle and distance between the output aperture and the ground are adjustable to accommodate test receivers of varying geometry. Use of off-the-shelf structural, lighting and electrical components keeps the fabrication cost below $\$ 10,000$.

Keywords: solar simulator; concentrating solar power; metal halide lighting; volumetric receiver; molten salts

Abbreviations:

CSP Concentrating Solar Power

FLC Flow Line Concentrator

NEMA National Electrical Manufacturers Association

NREL National Renewable Energy Laboratory

MH Metal Halide

Symbols:

$\begin{array}{ll}\alpha & \text { thermal diffusivity } \\ \alpha_{\text {solar }} & \text { solar absorptivity } \\ \beta & \text { volumetric coefficient of thermal expansion } \\ \theta & \text { cone half-angle } \\ \sigma & \text { Stefan-Boltzmann constant } \\ \varepsilon_{n} & \text { normal spectral emissivity } \\ v & \text { kinematic viscosity } \\ a & \text { secondary concentrator exit (aperture) radius } \\ A & \text { absorber area } \\ C & \text { secondary concentrator entrance radius } \\ D & \text { diameter }\end{array}$




$\begin{array}{ll}g & \text { gravitational acceleration } \\ h_{m} & \text { convection coefficient } \\ k & \text { thermal conductivity, air } \\ k_{A l} & \text { thermal conductivity, aluminum } \\ L & \text { characteristic length } \\ T & \text { absorber temperature } \\ T_{m} & \text { mean air temperature } \\ T_{\infty} & \text { ambient temperature } \\ V & \text { absorber volume } \\ q & \text { heat flux }\end{array}$

\section{Introduction}

Solar simulators are invaluable for solar energy research. Commercial off-the-shelf simulators are designed to provide small areas of uniform, nearly collimated light, matched to terrestrial solar spectra for photovoltaic (PV) cell testing. Typical flux output intensities are a few 'suns' $\left(1 \mathrm{sun}=1 \mathrm{~kW} / \mathrm{m}^{2}\right)$; thus they do not usually provide the high intensities required for concentrating solar power (CSP) testing. Custom made solar simulators have been built to provide the intensities necessary for CSP research, ranging from $30-100 \mathrm{~kW} / \mathrm{m}^{2}$ (30-100 suns) and upward, but have cost hundreds of thousands of dollars. These research simulators utilize high power xenon arc lamps, precision engineered optical elements and active cooling circuits (Hirsch et al, 2003, Jaworske, 1996, Kuhn, 1991, Petrasch et al, 2007).

This paper describes the design, development, and testing of a low-cost solar simulator, and plans for its construction are provided in the appendix. The goal for this project was to design and build a solar simulator for under $\$ 10,000$ that would offer similar testing capabilities to more expensive, high-flux research simulators. The only drawback is that the light is not well collimated with the simple concentrating optics that are employed. Although the unit is designed for CSP thermal testing, specifically to study the absorption behavior of volumetric molten salt receivers, it could be utilized for concentrated PV testing provided collimated light was not needed.

\section{Detailed Design}

The design of the solar simulator can be broken down into three subsystems: light source; adjustment structure; and concentrator. Table 1 lists the primary functional requirements and associated specification targets for the solar simulator. Figure 1 shows the completed simulator.

Table 1: Functional Requirements \& Design Specifications

\begin{tabular}{lll}
\hline $\begin{array}{l}\text { Functional } \\
\text { Requirement }\end{array}$ & Design Parameter & Specification \\
\hline Emulate solar heating & $\begin{array}{l}\text { Metal halide lights with } \\
\text { metal reflective } \\
\text { concentrating optics }\end{array}$ & Output flux $\geq 50 \mathrm{~kW} / \mathrm{m}^{2}$ \\
$\begin{array}{l}\text { Adjustable for } \\
\text { different receivers }\end{array}$ & $\begin{array}{l}\text { Aperture Height } \\
\text { Adjustability via nested } \\
\text { perforated tubing }\end{array}$ & $0 \leq$ Aperture height $\leq 1 \mathrm{~m}$ \\
$\begin{array}{l}\text { Tiltable for non- } \\
\text { normal incidence }\end{array}$ & $\begin{array}{l}\text { Aperture Rotation pivot } \\
\text { Large output spot }\end{array}$ & $0^{\circ} \leq$ Aperture angle $\leq 90^{\circ}$ \\
Conical concentrator & Aperture diameter $\geq 20 \mathrm{~cm}$ \\
\hline
\end{tabular}



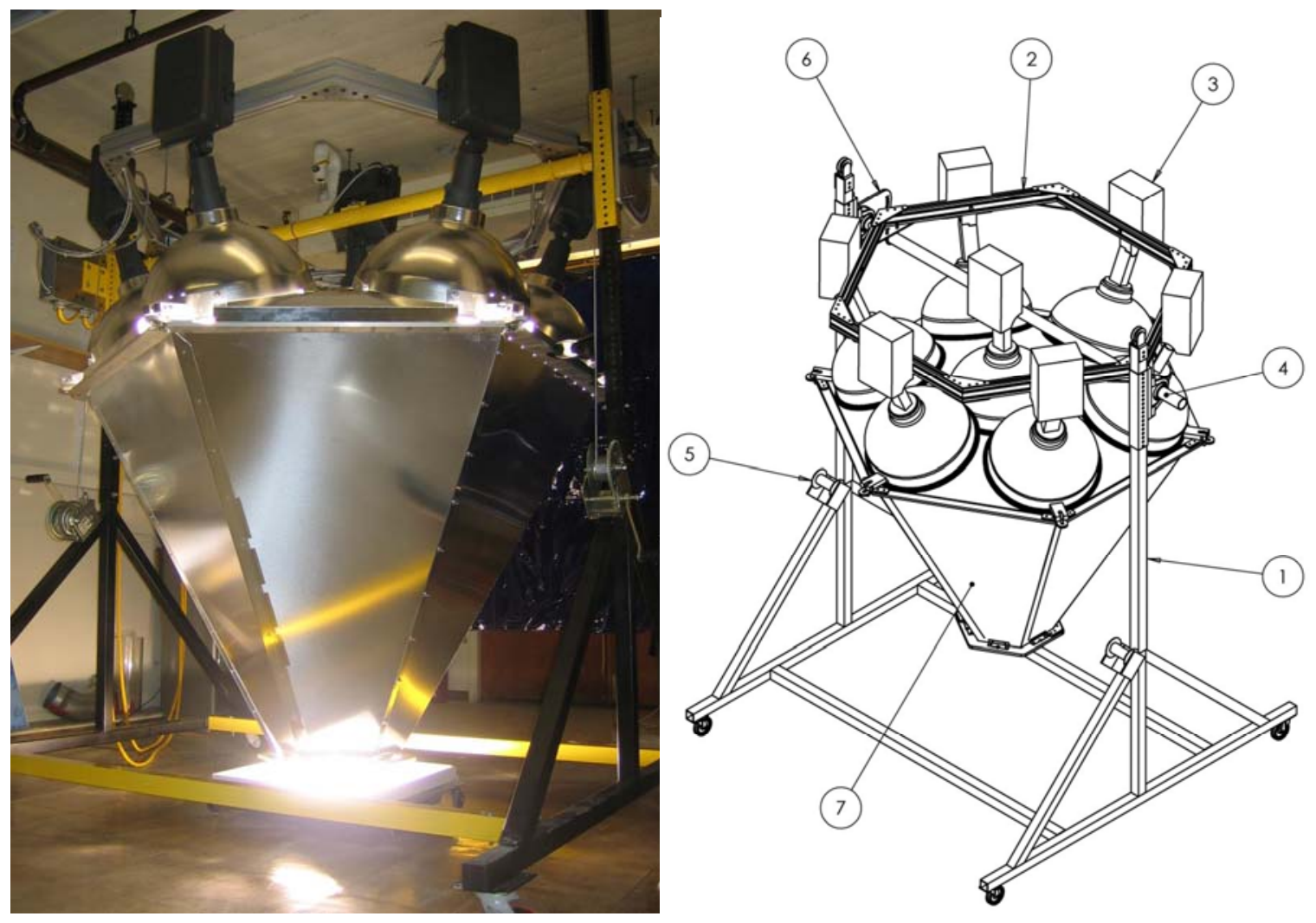

Figure 1: MIT Metal-Halide CSP Solar Simulator: $10.5 \mathrm{~kW} ; \varnothing 38 \mathrm{~cm}$ hexagonal output aperture; $2.1 \mathrm{~m}$ x $2.1 \mathrm{~m} \times 2.6 \mathrm{~m}(\mathrm{LxWxH})$ overall size. Subassemblies: (1) Frame; (2) Light Mounting Frame; (3) MH Light; (4) Pivot Tube; (5) Lifting Winch; (6) Tilt Adjustment Plate; (7) Secondary Concentrator.

\subsection{Light Source}

Xenon arc lamps, favored by commercial solar simulator manufacturers, can be filtered to have an emission spectrum closely matching that of terrestrial sunlight. They are available in high power single bulb configurations which can be coupled with a single ellipsoidal mirror, resulting in a tightly controlled spot size (Petrasch et al, 2007). However, high power xenon arc lamps and their associated drive electronics are expensive products, with nearly 10 times the costs-per-watt than commodity light sources.

Metal halide $(\mathrm{MH})$ lamps were determined to be the most practical light source due to the significant price difference. However, MH lamps come with quite a few drawbacks worth mentioning, although they were determined not to be detrimental to our CSP testing needs. The 'unfiltered' emission spectrum of does not match the emission spectrum of sunlight as closely as that of xenon arc lamps (see Figure 7 in the Testing \& Characterization section). Also, the long 'filament' in large MH bulbs does not lend itself to precise focusing - resulting in an increased minimum achievable spot size relative to xenon arc lamps.

MH lamps are widely used in industrial and sports lighting applications, and are thus readily available and inexpensive. Common MH outdoor stadium lights utilize 1500_W BT-56 bulbs and NEMA standardized spunaluminum ellipsoidal reflector geometries. Light distribution is described by NEMA 1-6 type ratings: Type 1 is a narrow beam $\left(10-18^{\circ}\right)$; Type 6 is a wide flood $\left(100-130^{\circ}\right)$ (Benya et al, 2003). Figure 2 shows the luminous intensity distributions for the most common types, NEMA 3 and 5. NEMA 3 reflectors were chosen for their narrow, high intensity output beam. 


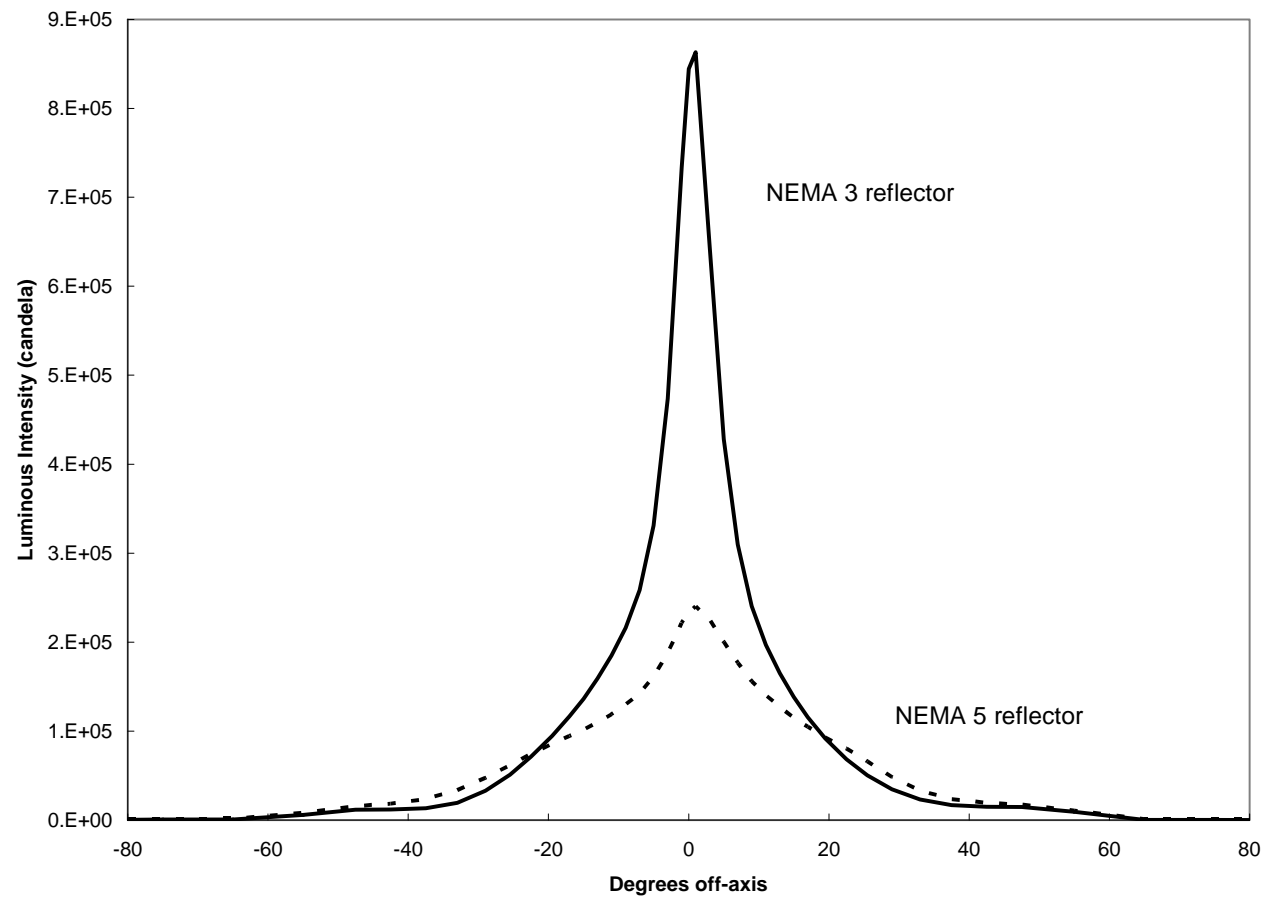

Figure 2: Luminous intensity distribution for $1500 \mathrm{~W}$ MH sports lighting fixtures with NEMA 3 and NEMA 5 ellipsoidal reflector geometry. (Photometric data from Hubbel Lighting, Inc, 2004)

Seven off-the-shelf (Complete Lighting Source: p/n SP1500MHMT) $1500 \mathrm{~W}$ outdoor MH units with integral ballasts, adjustable mounts and NEMA 3 reflectors are utilized for the solar simulator. The lights are arranged in a hexagonal array with the seventh light in the center. The simulator is configured for two $30 \mathrm{~A} / 208 \mathrm{~V}$ power sources with fused safety cut-off switches and individual circuit breaker and in-line fuse protection.

\subsection{Adjustment Structure}

The frame must be easy to assemble, stiff, and support the weight for the MH lights, ballasts and secondary concentrator - about $160 \mathrm{~kg}$. The frame also must be designed for ease of adjustment, disassembly and short range mobility so it can be moved within the lab, or between laboratories.

\subsubsection{Base}

Perforated steel tubing was chosen for its strength, stiffness, availability, low cost, and ability to safely set components at different heights with positive engagement pins. For portability, the frame is designed to separate into two A-frame style halves. The frame footprint measures approximately $2.1 \mathrm{~m} \times 2.1 \mathrm{~m}$. The base is equipped with casters for short-range mobility while assembled.

\subsubsection{Adjustable Height}

To accommodate test receivers/absorbers of various heights, perforated steel sleeves are employed over the frame uprights. The sliding sleeve assemblies are positioned using frame mounted load-lifting hand winches with integral safety brakes. Steel wire rope is used for the winches, extended over pulleys mounted to the top of each upright support and attached to an eyebolt on each sliding sleeve assembly. (Figure 3) 7/16" (11.1 mm) diameter zinc-plated steel quick release pins are used to lock the height adjustment sleeves in place. 


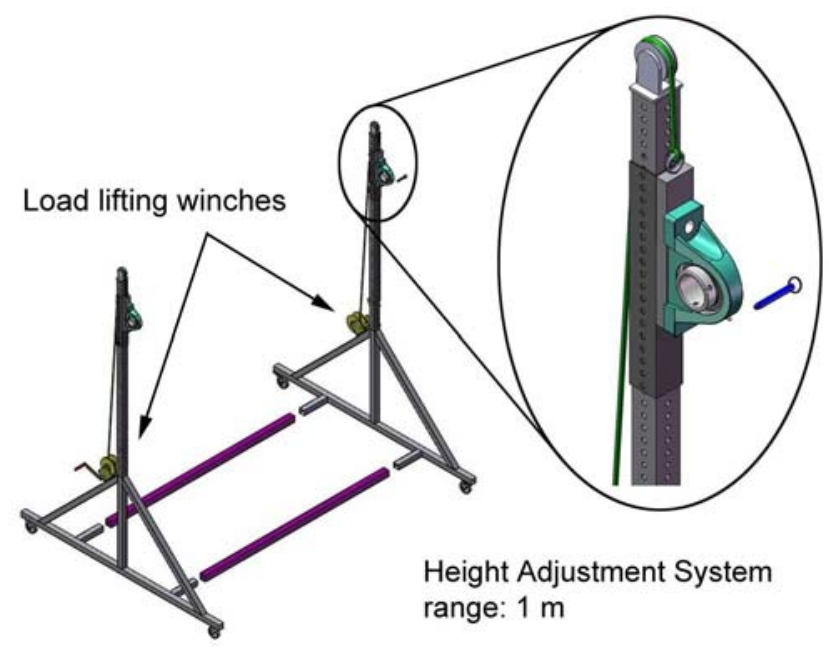

Figure 3: Simulator support frame (above) and nestable, perforated square tubing with pillow block bearing mount for height adjustments (right). Vertical adjustments accomplished with load-lifting winches $(2 \mathrm{X})$, located on support uprights.

\subsubsection{Rotatable output}

The simulator was designed to rotate about a horizontal axis to enable testing of various CSP receiver designs, some requiring non-vertical illumination - particularly the case of glancing angle irradiation over a liquid free-surface. Aluminum extrusions are assembled into a lightweight hexagonal frame, allowing direct mounting of the six peripheral MH light/ballast modules in a compact arrangement to enable pivoting of the entire light assembly.

The hexagonal frame assembly is mounted to a 2" schedule 40 (60.3 $\mathrm{mm}$ OD x $3.9 \mathrm{~mm}$ wall) steel pipe, supported on both ends by pillow-block mounted bearings. The central MH light is bolted to a bracket welded directly to the pipe's midsection. The pipe and aluminum extrusions were sized to keep deflection of the frame to a minimum, regardless of the tilt position. Efforts were made to keep the unit balanced so manual tilt adjustments can be made easily. An aluminum adjusting plate was designed to lock the simulator's rotation angle at 5 degree increments, and attached to the pipe with a captive stainless steel torque rod loaded in double shear (Figure 4). The torque rod serves as a "fuse" yielding to prevent tip-overs at torque of 11,800 lb-in $(1,333 \mathrm{~N}-\mathrm{m})$, corresponding to a eccentric load of $380 \mathrm{lb}(1.69 \mathrm{kN})$ applied at the edge of the 62" $(1.6 \mathrm{~m})$ wide light support frame. A single 7/16" $(11.1 \mathrm{~mm})$ diameter steel quick release pin locks the angular adjustment. The quick release pins are rated for 13,230 $\mathrm{lb}(58.8 \mathrm{kN})$ in single shear, which equates to a maximum load capacity of $3,400 \mathrm{lb}(15.1 \mathrm{kN})$ at the outer extremes of the light support frame, more than adequate for the lights and mounting structure.

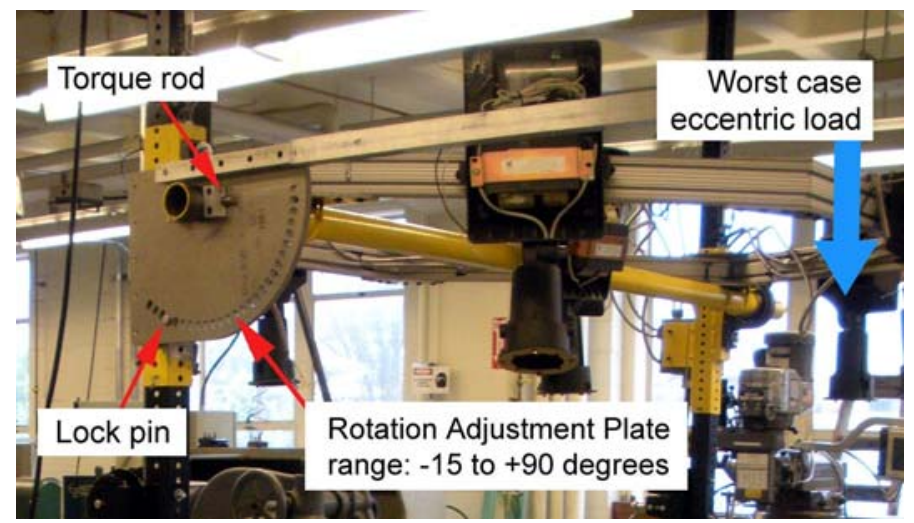

Figure 4: Rotation adjustment plate attached to MH support assembly, consisting of a steel 2" schedule 40 pipe mounted in pillow-block self aligning bearings, supporting the hexagonal aluminum extrusion light support structure. 


\subsection{Secondary Concentrator}

A simplified secondary concentrator is utilized to boost the flux available at the output aperture. Designs of non-imaging concentrators are well known - typical designs are variants of compound parabolic concentrators (CPCs) or flow-line concentrators (FLCs), as shown in Figure 5 (Winter et al, 1991). A truncated FLC was selected for the simulator, resulting in a hexagonal conical structure with reasonable concentration performance that is very simple to manufacture.

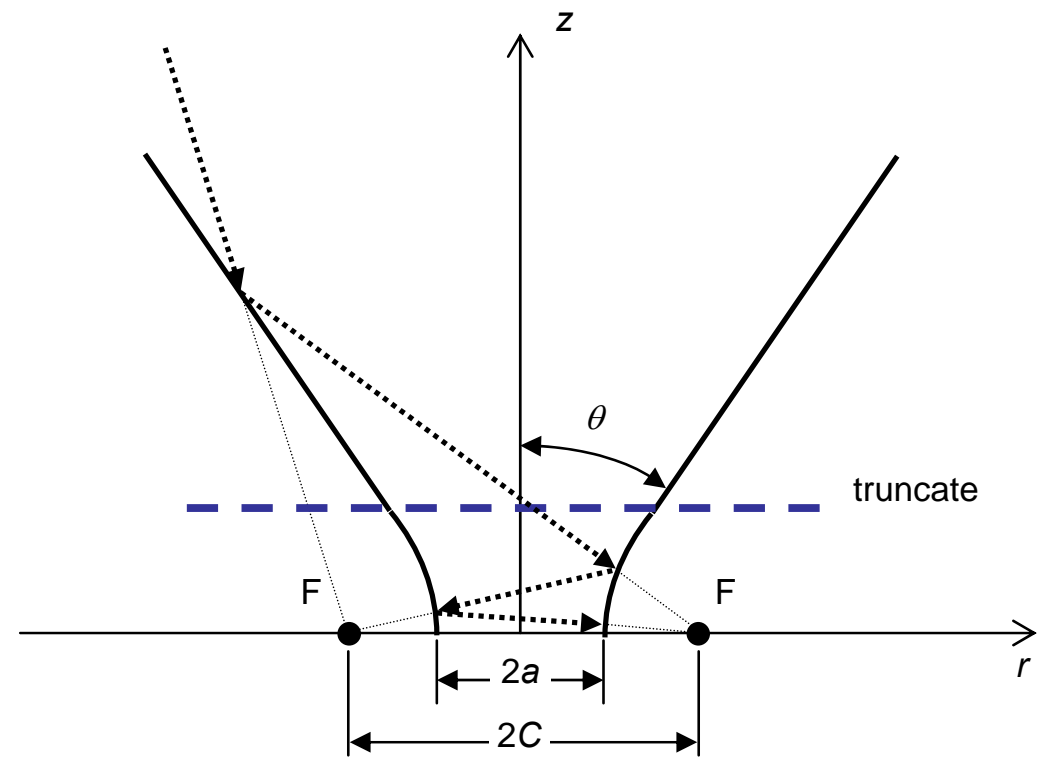

Figure 5: Flow-Line Concentrator geometry; simplified flat-cone construction along hyperbolic asymptotes is utilized for the solar simulator. The asymptotes have a half angle $\theta$ relative to the $z$-axis. Flux aimed between $\pm C$ will be concentrated on to $\pm a$, resulting in a concentration of $C / a\left(C^{2} / a^{2}\right.$ for a hyperboloid of revolution). After Winter et al (1991).

As noted in the design of flat 2-dimensional cone concentrators, there is a distinct tradeoff between increased concentration, number of reflections, and the length of the concentrator. SolTrace, NREL's ray-tracing freeware, was used to simulate the optical performance of the secondary concentrator. However, the software did not allow for individual light sources (i.e., the array of seven MH lights) to be defined, so the entrance plane of secondary concentrator was illuminated with uniform, collimated input flux. Simulated output flux results are shown in Figure 6 for the conical design geometry, with a $24.9^{\circ}$ half-angle. Predicted concentration across the output aperture is boosted with noticeably increased concentration in the center. 


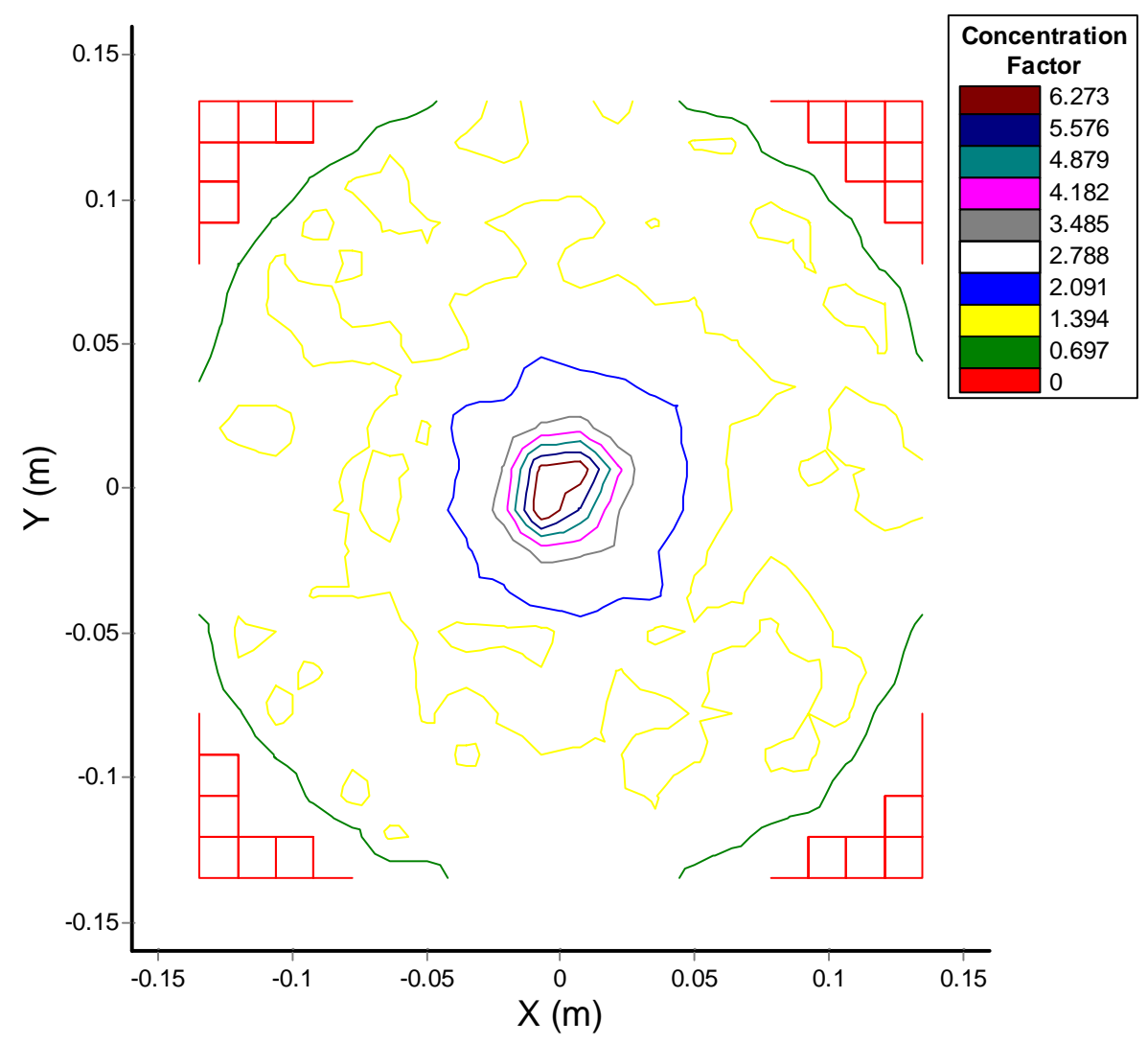

Figure 6: Output aperture flux concentration ray-tracing simulation results, concentration ratio (output flux/input flux) at exit aperture of secondary concentrator. $24.9^{\circ}$ conical secondary concentrator geometry; 300,000 rays with a uniform input flux directed parallel to the concentrator's $z$-axis. A "hot spot" of over $6 \mathrm{x}$ concentration is predicted in the center of the output aperture.

Commercial specular reflective 'bright' anodized aluminum (Lorin Industries "ClearBrite" ${ }^{\circledR}$ " $1 \mathrm{~mm}$ thick $5657-\mathrm{H} 25 \mathrm{Al}$ ) used in custom signs and lighting was chosen for the concentrator panels for its low cost, low mass and excellent heat dissipation characteristics. An aluminum frame was fabricated top and bottom for rigidity and ease of attachment to the lights. Additional provisions were made on the output aperture frame for mounting a hyperboloidal 'neck' to further boost the concentration, if needed for future tests. Contoured aluminum adapter plates are used to distribute the stress of the concentrator load without deforming the thin MH primary reflectors, and top 'filler' reflectors close the gaps between the MH lights. (Figure 7)

It was assumed that natural convection over the concentrator's large outside surface would be sufficient to prevent overheating inside a climate-controlled laboratory environment with ambient temperatures near $25^{\circ} \mathrm{C}$. For example, a worst case calculation of all the input power $(10.5 \mathrm{~kW})$ reflected an average of two times over the secondary concentrator (assumed reflectivity $=0.89$; surface area $=4.9 \mathrm{~m}^{2}$ ) gives a heat flux of only $450 \mathrm{~W} / \mathrm{m}^{2}-$ much less than midday sun.

During operation, the upper portions of the simulator, including the primary $\mathrm{MH}$ light reflectors and the top of secondary concentrator, become slightly warm to the touch. However, during periods of prolonged operation exceeding several hours, the bottom $10 \mathrm{~cm}$ of the concentrator reaches temperatures of $140^{\circ} \mathrm{C}$. This is expected, as there are an increased number of reflections near the output aperture and heat from the receiver can conduct into the 
secondary concentrator. If needed, the concentrator's operating temperature can be reduced by adding external finned surfaces or water cooling the distal end of the panels, or cooling the output aperture mounting frame directly.

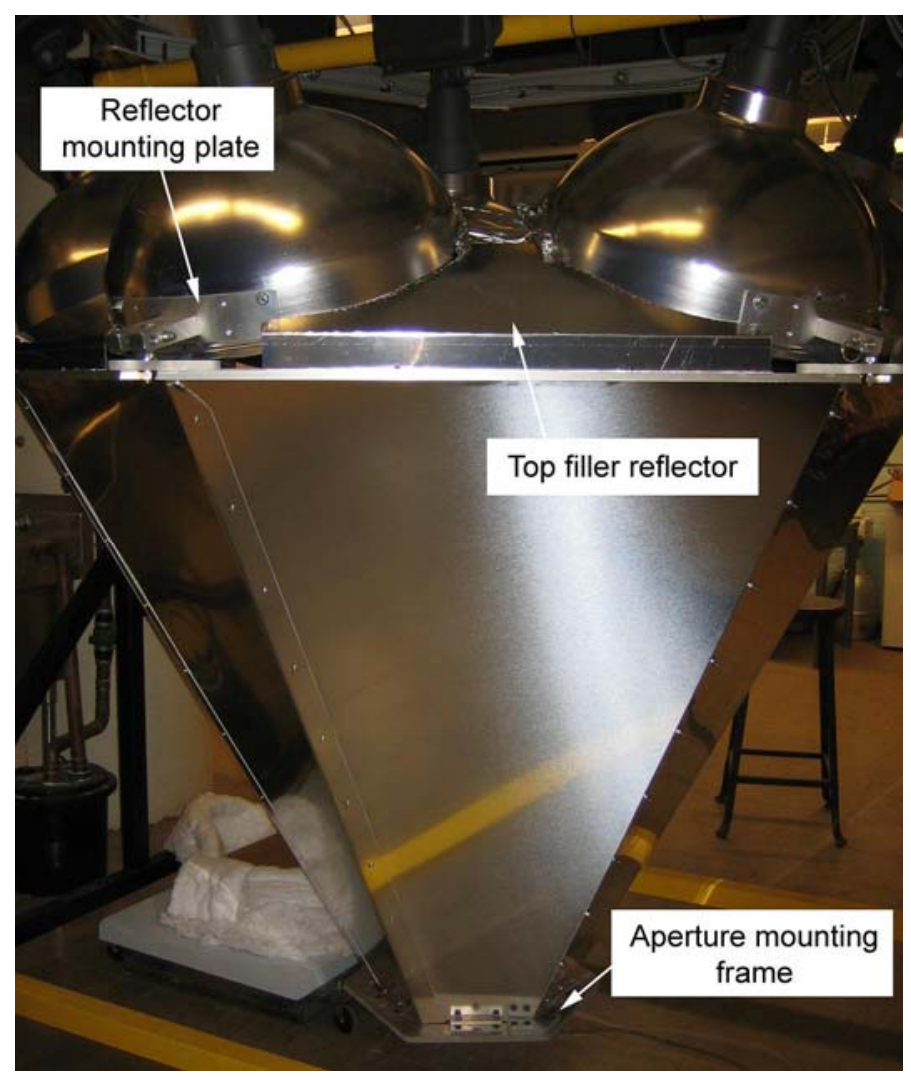

Figure 7: Secondary concentrator structure. Mounting plates distribute the load evenly on the reflector domes to avoid distortion. Specular anodized aluminum sheet ( $1 \mathrm{~mm}$ thickness) is utilized for the reflective surfaces. 


\section{Testing \& Characterization}

After the solar simulator was assembled, the following tests were performed to determine its suitability for use in our CSP testing: solar spectral match and flux intensity determination.

\subsection{Spectral Distribution}

An Ocean Optics USB 650 spectrometer was used to compare the simulator output from 350-1000 nm (VIS-NIR) to midday sun. A pinhole aperture was placed over the sensor to avoid saturating the spectrometer while collecting the simulator's spectra. As shown in Figure 8, the spectral intensity of the simulator - while not a perfect match for sunlight - is a reasonable approximation in the range tested. The NIR intensity peaks typical of MH lights are clearly visible beyond $800 \mathrm{~nm}$. The MIT CSP simulator delivers $10.9 \%$ of its $350-1000 \mathrm{~nm}$ energy in the $800-$ $1000 \mathrm{~nm}$ range, as opposed to the sun's measured $5.9 \%$ over the same range.

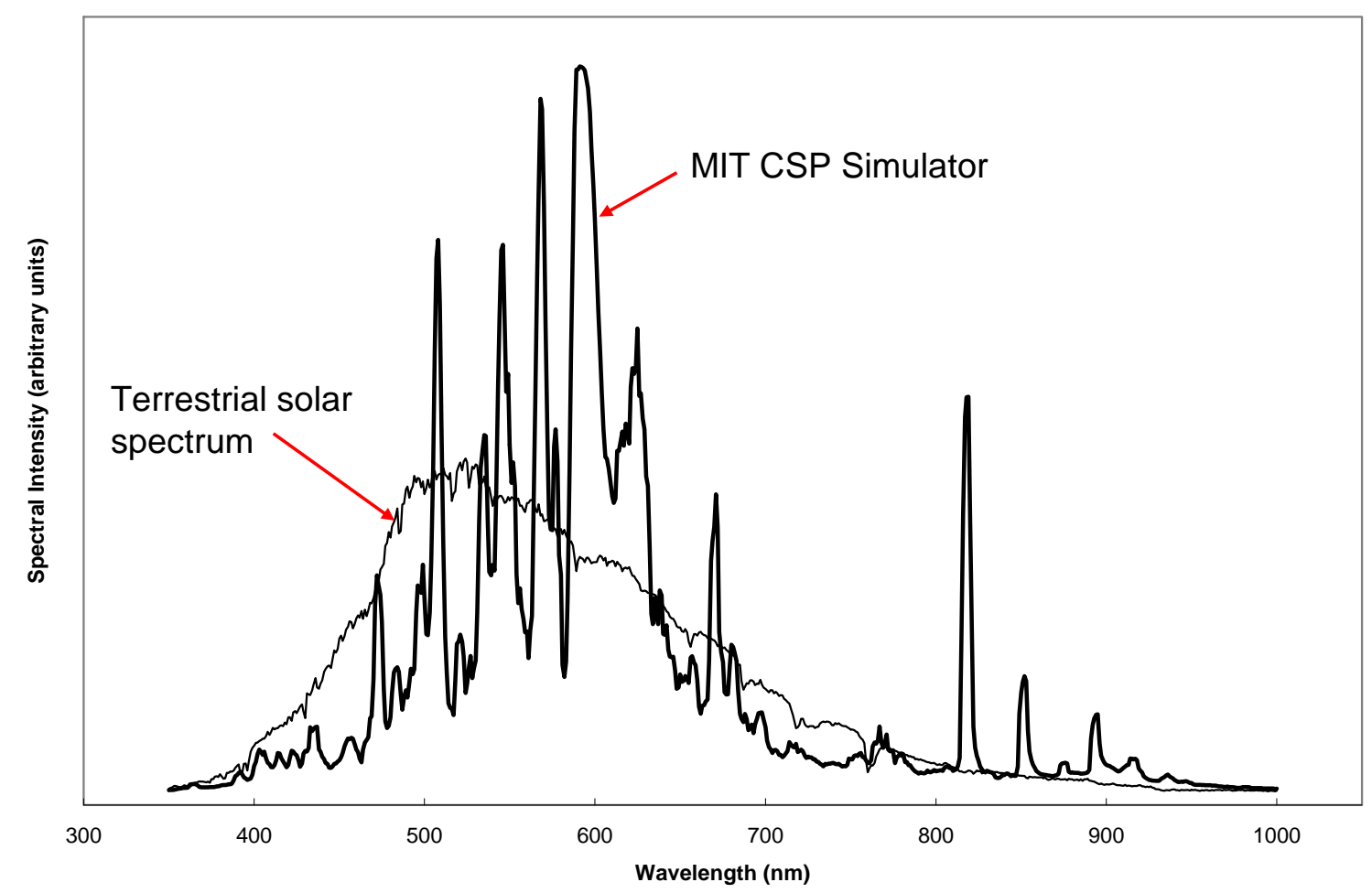

Figure 8: Spectral Intensity comparison for the MIT MH CSP simulator vs. measured midday sun spectra. All curves were normalized to result in identical intensities when integrated over the test spectrum: 350 to $1000 \mathrm{~nm}$.

\subsection{Intensity Distribution}

A simple calorimetric experiment was conducted to quantify the flux distribution across the output aperture. A flux gage was not available for use, so a small aluminum disc $(\varnothing 29.3 \mathrm{~mm}$ x $1.3 \mathrm{~mm}$ thick$)$ was instrumented with a thermocouple and placed in the output aperture. Figure 9 plots the transient temperature behavior of the disc at various radial positions across the output aperture. After only 20 minutes under the simulator lights, the absorber disc temperature approached steady-state values. Between each measurement run, the simulator was turned off and allowed to cool to ambient temperature. The absorber disc was examined after each run, but did not exhibit any noticeable change in appearance or oxidation discoloration. As expected, the peak temperature is reduced as the absorber was moved away from the center of the output aperture. 


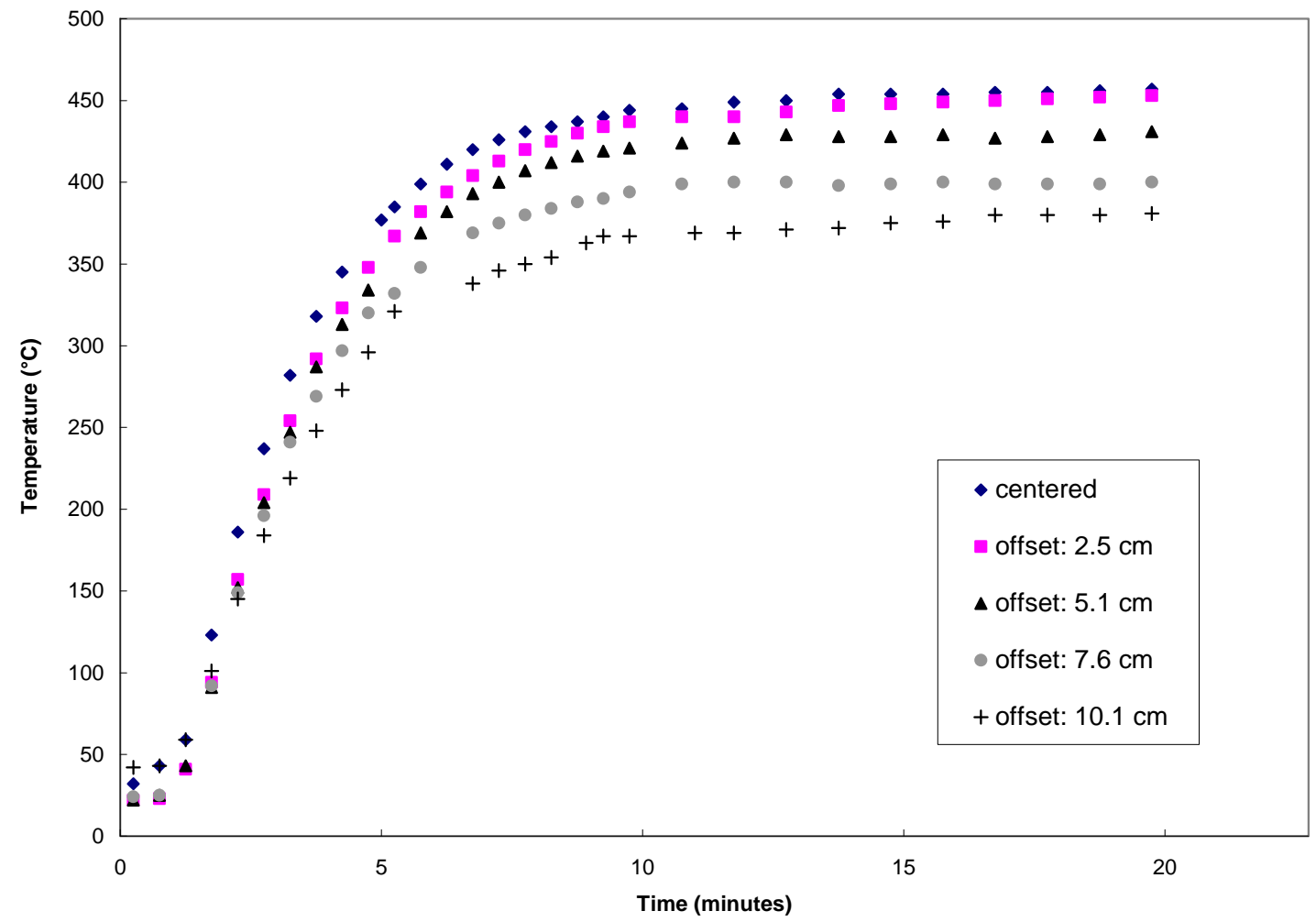

Figure 9: Absorber Target Temperature: Al sheet disc, $\varnothing 29.3 \mathrm{~mm}$ x $1.3 \mathrm{~mm}$ thick, mill finish. Note decreasing temperatures as the target is radially offset from the center of the output aperture.

The small, conductive disc is assumed to be at a uniform temperature, which gives an indication of the average flux received onto its surface. Assuming steady-state conditions, a simple energy balance can be used to calculate the incoming flux in terms of the absorber temperature and its surface properties.

The energy balance diagram is shown in Figure 10. Since the disc was placed on a thick layer of ceramic fiber insulation and the aperture opening was lowered onto this insulation blanket, the horizontal disc can be modeled as well-insulated on the back side and without forced convection losses on the top surface. However, the hot disc promotes free convection to develop on its surface, and radiates heat to its lower temperature surroundings. The thin edge area of the absorber disc is ignored for these calculations.

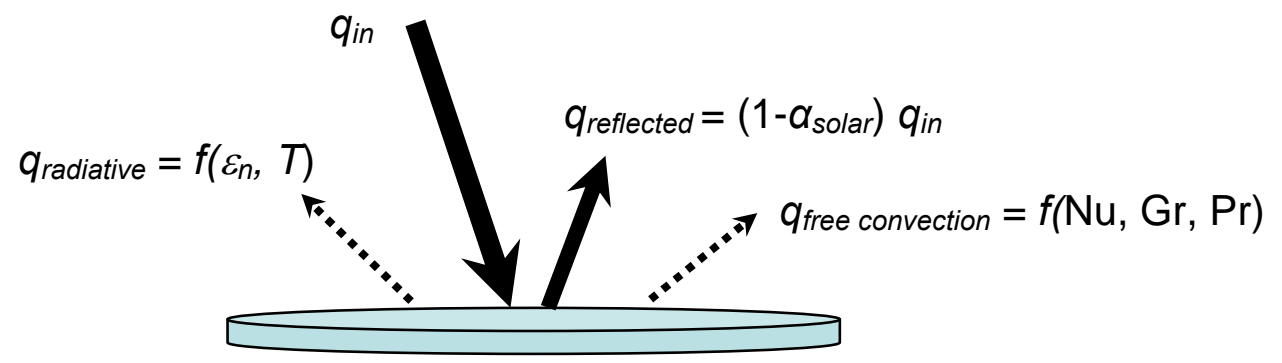

Figure 10: Heat flux balance for top surface of horizontal absorber test target. Back side is insulated. 
Free convection losses can be estimated using correlations for natural convection above heated horizontal discs. These can be found in standard heat transfer textbooks and are of the form:

$$
\mathrm{Nu}_{\mathrm{m}}=c(\mathrm{Gr} \cdot \mathrm{Pr})^{n}
$$

The correlation coefficients for laminar flow over a hot horizontal plate given as $c=0.54$ and $n=1 / 4$. (Ozisik, 1985) $\mathrm{Nu}$ is the Nusselt number, Gr is the Grashof number and Pr is the Prandtl number, evaluated at the mean air temperature, $T_{m}$ and defined as:

$$
\begin{aligned}
& \mathrm{Nu}_{\mathrm{m}}=h_{m} \cdot L / k \\
& \mathrm{Gr}=g \beta L^{3}\left(T-T_{\infty}\right) / v^{2} \\
& \mathrm{Pr}=v / \alpha \\
& T_{m}=\left(T+T_{\infty}\right) / 2
\end{aligned}
$$

where

$$
\beta=1 / T_{m}
$$

In the case of a horizontal circular disc of diameter $D$, the characteristic length $L$ to be used in Equations 2 and 3 is:

$$
L=0.9 D
$$

The free convection and radiative heat flux losses are calculated as:

$$
\begin{aligned}
& q_{\text {free convection }}=h_{m}\left(T-T_{\infty}\right) \\
& q_{\text {radiative }}=\varepsilon_{n} \sigma\left(T^{4}-T_{\infty}^{4}\right)
\end{aligned}
$$

The reflected heat flux, where $\alpha_{\text {solar }}$ is the disc's solar spectrum absorptivity, is simply:

$$
q_{\text {reflected }}=\left(1-\alpha_{\text {solar }}\right) \cdot q_{\text {in }}
$$

The energy balance for the disc is:

$$
q_{\text {in }}=q_{\text {reflected }}+q_{\text {radiative }}+q_{\text {free convection }}
$$

combining Equations $9 \& 10$ and solving for the incoming flux provided by the simulator:

$$
q_{\text {in }}=\left(1 / \alpha_{\text {solar }}\right) \cdot\left(q_{\text {radiative }}+q_{\text {free convection }}\right)
$$

A Biot number $<<0.1$, validates the assumption of the target disc as a lumped mass of uniform temperature. With the thermal conductivity of the disc denoted by $k_{A l}$, the Biot number, $\mathrm{Bi}$, is defined as:

$$
\mathrm{Bi}=h_{m} \cdot L / k_{A l}
$$

Calculated values for the absorber disc at each test position are presented in the appendix. The calculated output intensity at various radial positions is shown in Figure 11. As expected, calculated optical power is greatest at the center of the output aperture. However, the ray-tracing predicted central "hot spot" was not observed, with calculated values decreasing only slightly as a function of the radial offset from center. One explanation for this discrepancy could be the ray-tracing modeling limitations which could not capture the seven discrete, aimed MH light sources - but instead required the use of a uniform input beam. 
It is worth noting the various sources of uncertainty in the above calculations; particularly the effects of ambient temperature $\left(T_{\infty}\right)$ and the absorber disc's surface properties $\left(\alpha_{\text {solar }}\right.$ and $\left.\varepsilon_{n}\right)$. Before each run, the simulator and secondary concentrator were allowed to cool to the ambient temperature of the room, approximately $25^{\circ} \mathrm{C}$. The measurement runs were short, only 20 minutes duration, and the base of the secondary concentrator did not exceed $50^{\circ} \mathrm{C}$ at the end of each run. Setting $T_{\infty}=50^{\circ} \mathrm{C}$ (as opposed to $T_{\infty}=25^{\circ} \mathrm{C}$ ) equates to $6 \%, 1 \%$ and $6 \%$ difference in the values of flux calculated in Equations 8, 9 and 12, respectively.

The absorber disc surface property uncertainty has a much greater effect on the calculated performance. Tabulated values were used for the solar absorptivity and normal spectral emissivity of mill finish aluminum sheet. Ozisik (1985) lists $\alpha_{\text {solar }}=0.14$ and $\varepsilon_{n}=0.06$, while Love (1968) shows $\alpha_{\text {solar }}=0.11$ and $\varepsilon_{n}=0.05$. This large variation in the solar absorptivity (21\%) translates to an equally large variation in calculated flux. In addition, the spectral output of the simulator does not match that of the sun exactly, and one would expect a slightly different value for the effective "simulator absorptivity" of the aluminum absorber disc. Because the simulator has additional spectral output in the near infrared region, the "simulator absorptivity" should be bounded somewhere between the spectral emissivity (NIR-IR) and solar absorptivity (VIS-NIR). For this reason, the absorber disc's nominal values were set to those defined by Love, $\alpha_{\text {solar }}=0.11$ and $\varepsilon_{n}=0.05$. Bounding lines are shown on Figure 11 for Ozizik's values and the limiting case defined by Kirchhoff's law: $\varepsilon_{n}=\alpha_{\text {solar }}=0.11$.

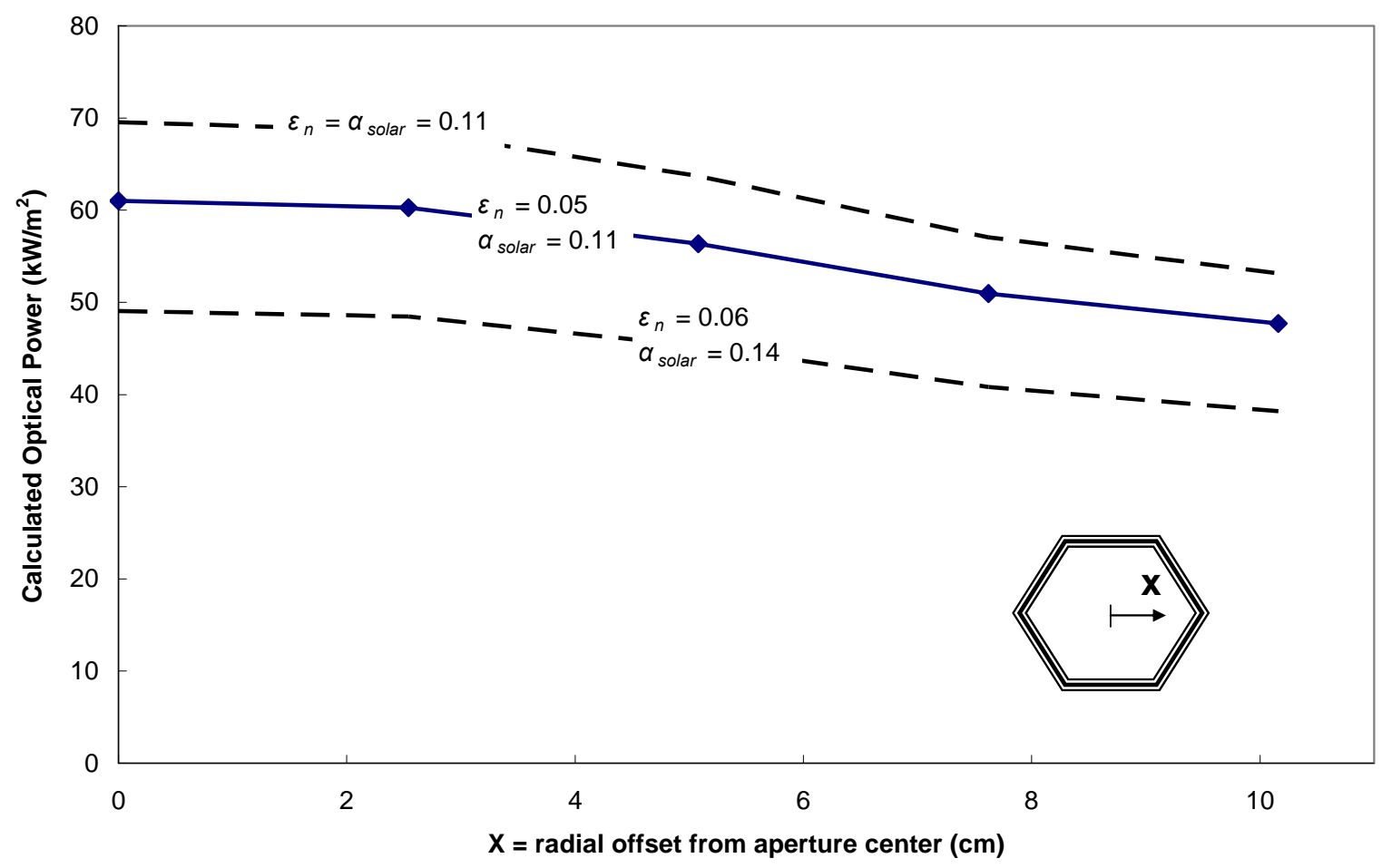

Figure 11: Calculated aperture flux distribution, accounting for free-convection and radiative losses of the test target. Al sheet disc absorber, $\varnothing 29.3 \mathrm{~mm} \times 1.3 \mathrm{~mm}$ thick, mill finish. Heavy solid line corresponds to absorber disc spectral emissivity, $\varepsilon_{n}=0.05$, and solar absorptivity, $\alpha_{\text {solar }}=0.11$ (Love, 1968). Bounding dotted lines correspond to $\varepsilon_{n}=0.06, \alpha_{\text {solar }}=0.14$ (Ozisik, 1985) and $\varepsilon_{n}=\alpha_{\text {solar }}=0.11$. 


\section{Component Costs}

The costs of the major subassemblies are detailed in the bill-of-materials listed in the appendix. Direct material cost for the simulator is under $\$ 5,000$.

\section{Molten Salt Volumetric Receiver Testing}

Preliminary optical heating tests of molten salt receivers were performed using the MIT CSP Solar Simulator. Figures $12 \& 13$ depict the setup, examining the temperature distribution of industrial-grade molten nitrate salt (Coastal Chemical "Hitec Solar Salt" 60/40 wt\% Na-K NO3 mixture; melting temperature $220-240^{\circ} \mathrm{C}$ ). A well-insulated 316L stainless steel receiver, $67 \mathrm{~mm}$ inner diameter x $250 \mathrm{~mm}$ long, was instrumented along its length with eight type $\mathrm{K}$ sheathed thermocouples. Four thermocouples protrude into the volumetric receiver to measure centerline temperatures, while the remaining four measure are positioned near the receiver wall. (Figure 11) A low expansion, high strength reinforced silica matrix refractory board (Zircar RSLE-57) with a $63.5 \mathrm{~mm}$ aperture was mounted to the bottom of the concentrator to limit heating to the exposed salt surface. The salt mixture was premelted, then placed under the MIT CSP solar simulator and optically heated.

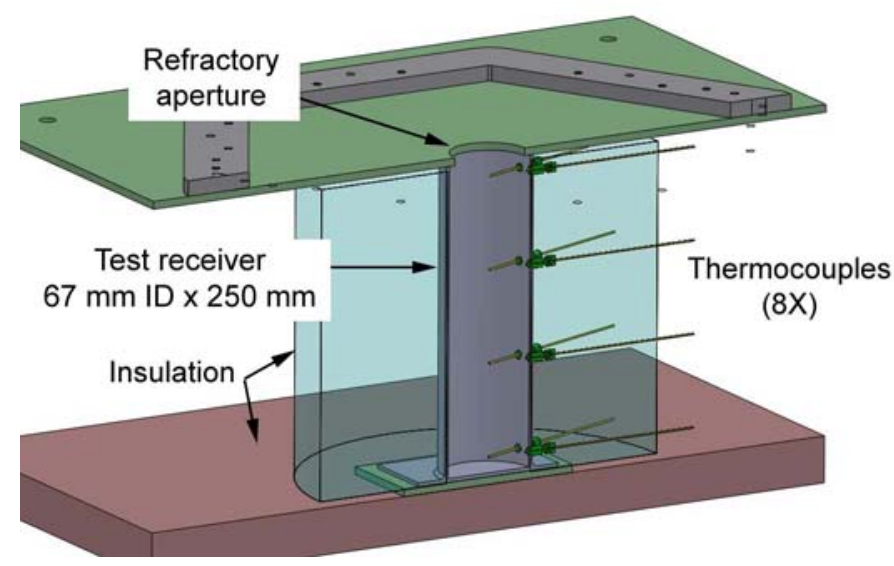

Figure 12: Schematic of molten salt volumetric receiver, for optical heating testing with molten nitrate $(60 / 40 \mathrm{Na}-\mathrm{K})$ salts. 


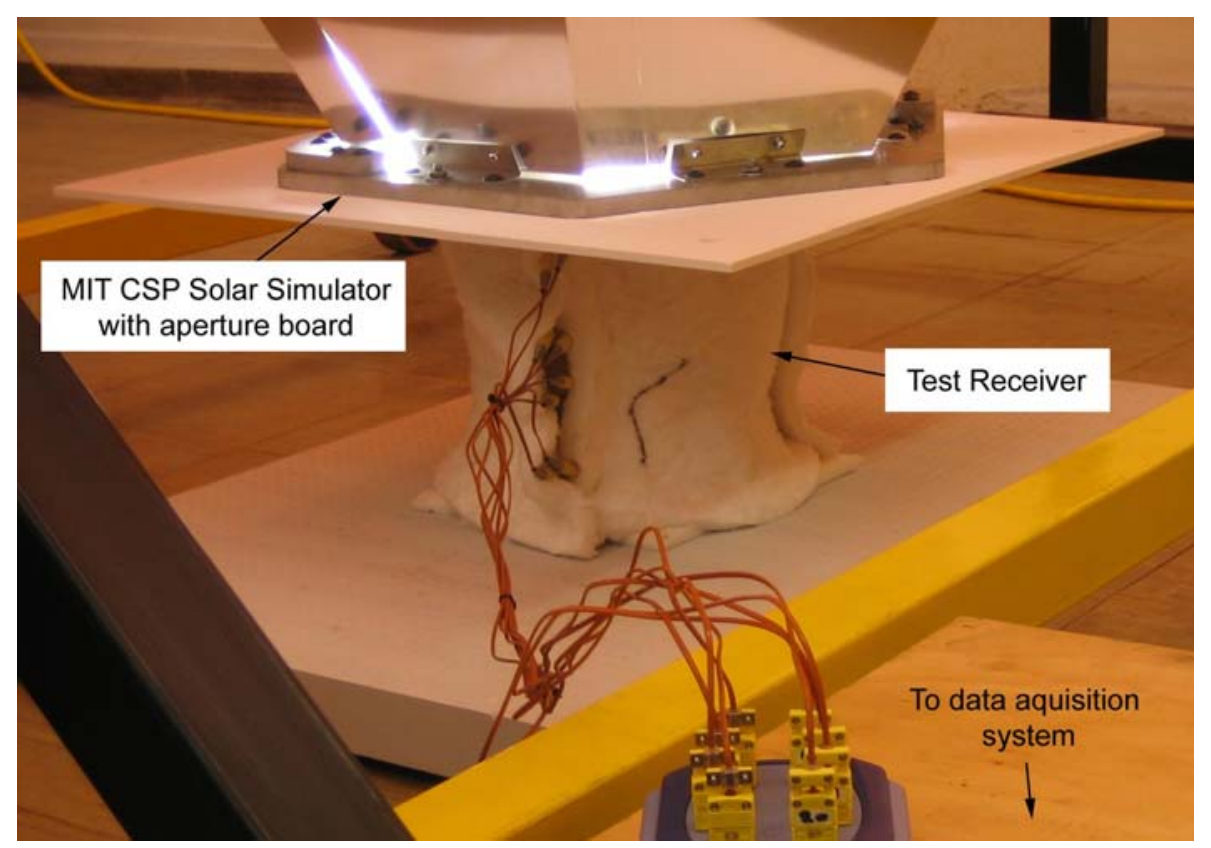

Figure 13: MIT CSP Solar Simulator with molten salt volumetric receiver at bottom.

The MIT CSP simulator was successful in heating the nitrate salt and keeping it molten. (Figure 14) Steady-state thermal stratification was observed, although the upper $80 \mathrm{~mm}$ of the salt was nearly at the same temperature as the surface. One explanation for this could be the divergent nature of the output rays, as shown in Figure 15. Due to the relative transparency of the molten salt (Figure 16), the absorptive receiver walls are heated selectively in this "fanned-out" upper region, keeping the top hot thickness greater than buoyancy effects alone. Further tests are planned for shallow, wide molten salt receivers that will fill the entire aperture area. 


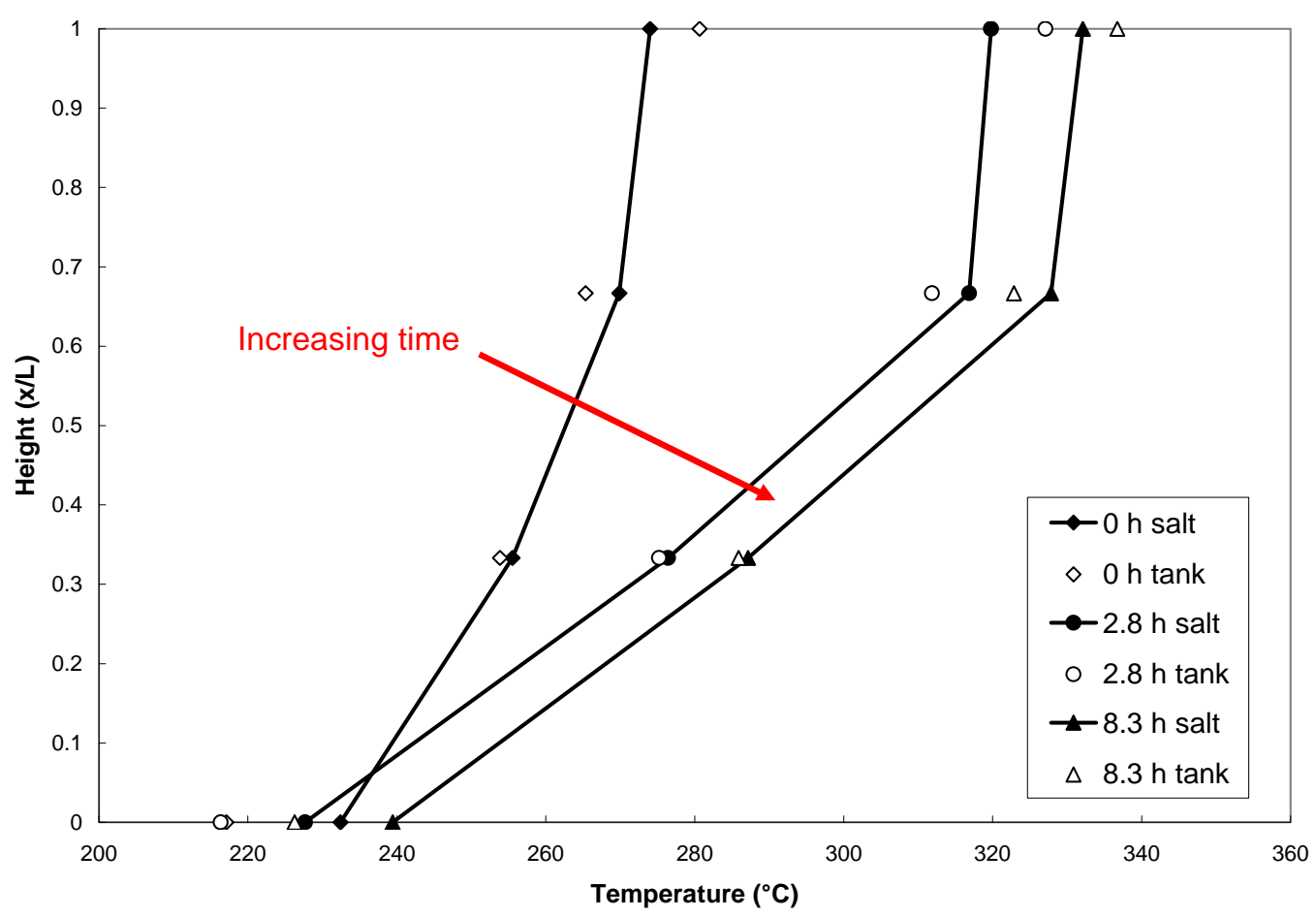

Figure 14: Temperature distribution of molten nitrate (60/40 Na-K) salt mixture heated by MIT CSP solar simulator.

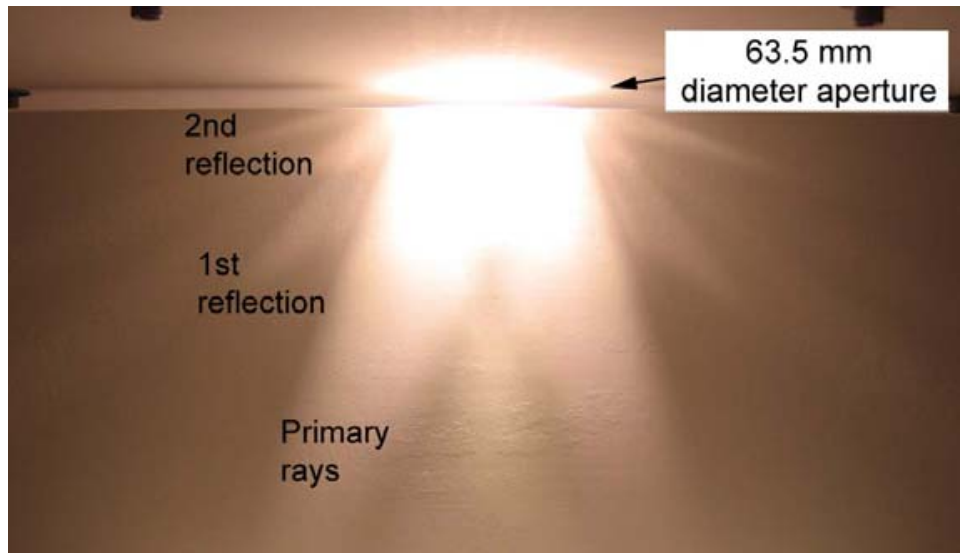

Figure 15: Appearance of output rays limited by a $63.5 \mathrm{~mm}$ aperture. Clearly visible are the primary (from the MH lights) and secondary (reflected from the concentrator) rays. The non-imaging nature of the concentrator results in divergent rays as they travel away from the aperture. 


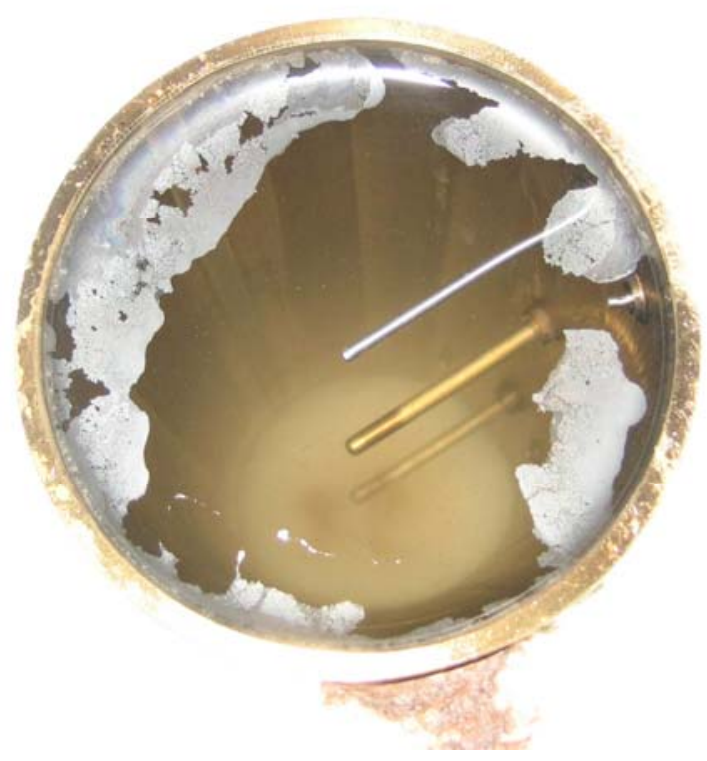

Figure 16: Molten Nitrate $(60 / 40 \mathrm{Na}-\mathrm{K})$ salt mixture in test volumetric receiver; premelted, then optically heated to $330^{\circ} \mathrm{C}$ by MIT CSP solar simulator - removed for photo. The molten nitrate salt mixutremixture is relatively transparent to visible light.

\section{Conclusion and Recommendations}

A low-cost solar simulator has been developed and tested successfully. It utilizes an array of seven $1500 \mathrm{~W}$ MH outdoor sporting lights. With the use of a secondary cone concentrator, output fluxes greater than $60 \mathrm{~kW} / \mathrm{m}^{2}(60$ suns) peak and $45 \mathrm{~kW} / \mathrm{m}^{2}$ (45 suns) average are achieved across the $38 \mathrm{~cm}$ diameter output aperture. In order to accommodate test receivers of varying geometry, the simulator's output aperture height and tilt angle are adjustable. The fabricated cost is kept below $\$ 10,000$ by extensive use of standard structural, lighting and electrical components.

Although the spectral output of the simulator is shown to be adequate for MIT's CSP molten salt receiver testing needs, filters could be placed over the reflector or concentrator apertures to adjust as needed - accompanied by more detailed spectrometry in the VIS-NIR-IR spectrum. The use of narrow beam NEMA 1 or custom spun primary reflectors would be a wise choice for increased output concentration; additional benefits could be obtained by adding a contoured hyperboliodal lip to the secondary concentrator output aperture. Further characterization of output irradiance could be performed in accordance with ASTM 927, "Standard Specification for Solar Simulation for Photovoltaic Testing" to classify the simulator for more widespread use, including concentrated PV testing. 
Role of the funding source:

The work presented in this paper is part of an interdisciplinary collaboration between the Cyprus Institute, the University of Illinois at Urbana Champaign, the Electricity Authority of Cyprus, and the Massachusetts Institute of Technology. This work would not have been possible without the generous support of the Chesonis Family Foundation whose fellowship enabled Daniel Codd to focus on concentrated solar power research.

\section{$\underline{\text { References: }}$}

Petrasch, J., Coray, P., Meier, A., Brack, M., Haberling, P., Wuillemin, D., Steinfeld, A., 2007. A novel 50 kW 11,000 suns high-flux solar simulator based on an array of xenon arc lamps. J. Solar Energy Engineering, 129(4), 405-411.

Hirsch, D., Zedtwitz, P., Osinga, T., Kinamore, J., Steinfeld, 2003. A new 75 kW high-flux solar simulator for hightemperature thermal and thermochemical research. J. Solar Energy Engineering, 125( 1), 117-120.

Kuhn, P., Hunt, A., 1991. A new solar simulator to study high temperature solid-state reactions with highly concentrated radiation. Solar Energy Materials, 24(1-4), 742-750.

Jaworske, D., Jefferies, K., Mason, L., 1996. Alignment and Initial Operation of an Advanced Solar Simulator. J. Spacecraft and Rockets, 33(6), 867-869.

Benya, J., Heschong, L., McGowan, T., Miller, N., Rubinstein, F., 2003. Advanced Lighting Guidelines. New Buildings Institute, Inc., White Salmon, WA.

Hubbel Lighting, 2004. Photometric Report, 7-20-2004, CAT NO.:, TEST NUMBERS: HP-09844 (SLS-1500Hxx3x), HP-09820 (SLS-1500Hx-x5x). Hubbel Lighting, Inc., Christiansburg, Virginia.

Winter, C., Sizmann, R., Vant-Hull, L., 1991. Solar Power Plants : Fundamentals, Technology, Systems, Economics. New York, Springer-Verlag.

Ozisik, M., 1985. Heat Transfer: A Basic Approach. New York, McGraw-Hill.

Love, T. J., 1968. Radiative heat transfer. Columbus, Ohio, C. E. Merrill Pub. Co. 
Appendix

A1. Representative flux calculations for the MIT CSP Solar Simulator

Table A1: Absorber disc properties

\begin{tabular}{llllll}
\hline disc diameter, & characteristic & ambient temp, & & & \\
$D(\mathrm{~m})$ & length, $L(\mathrm{~m})$ & $\mathrm{T}_{\infty}(\mathrm{K})$ & $\alpha_{\text {solar }}$ & $\varepsilon_{n}$ & $k_{A l}(\mathrm{~W} / \mathrm{m}-\mathrm{K})$ \\
\hline 0.0293 & 0.0264 & 298 & 0.11 & 0.05 & 164 \\
\hline
\end{tabular}

Table A2: Calculation of input flux values

\begin{tabular}{|c|c|c|c|c|c|c|}
\hline & \multicolumn{5}{|c|}{ disc offset from center $(\mathrm{cm})$} & \multirow{2}{*}{$\begin{array}{l}\text { Equation } \\
\text { from text }\end{array}$} \\
\hline & 0.0 & 2.5 & 5.1 & 7.6 & 10.2 & \\
\hline $\begin{array}{l}\text { steady-state disc } \\
\text { temp, } T(\mathrm{~K})\end{array}$ & 730 & 726 & 704 & 673 & 654 & \\
\hline$T_{m}(\mathrm{~K})$ & 514 & 512 & 501 & 486 & 476 & (5) \\
\hline$v\left(\mathrm{~m}^{2} / \mathrm{s}\right)$ & $3.96 \mathrm{E}-05$ & $3.93 \mathrm{E}-05$ & $3.80 \mathrm{E}-05$ & $3.61 \mathrm{E}-05$ & $3.49 \mathrm{E}-05$ & \\
\hline$\alpha\left(\mathrm{m}^{2} / \mathrm{s}\right)$ & $5.87 \mathrm{E}-05$ & 5.84E-05 & 5.64E-05 & $5.36 \mathrm{E}-05$ & $5.20 \mathrm{E}-05$ & \\
\hline$k(\mathrm{~W} / \mathrm{m}-\mathrm{K})$ & 4.20E-02 & $4.18 \mathrm{E}-02$ & $4.11 \mathrm{E}-02$ & 4.01E-02 & $3.95 \mathrm{E}-02$ & \\
\hline $\operatorname{Pr}$ & 0.674 & 0.674 & 0.673 & 0.672 & 0.672 & (4) \\
\hline Gr & $9.64 \mathrm{E}+04$ & $9.71 \mathrm{E}+04$ & $1.01 \mathrm{E}+05$ & $1.07 \mathrm{E}+05$ & $1.10 \mathrm{E}+05$ & (3) \\
\hline $\mathrm{Nu}_{\mathrm{m}}$ & 8.62 & 8.64 & 8.72 & 8.84 & 8.91 & (1) \\
\hline$h_{m}\left(\mathrm{~W} / \mathrm{m}^{2}-\mathrm{K}\right)$ & 13.72 & 13.71 & 13.61 & 13.45 & 13.35 & (2) \\
\hline$q_{\text {free convection }}\left(\mathrm{kW} / \mathrm{m}^{2}\right)$ & 5.93 & 5.87 & 5.52 & 5.05 & 4.75 & (8) \\
\hline$q_{\text {radiative }}\left(\mathrm{kW} / \mathrm{m}^{2}\right)$ & 0.78 & 0.77 & 0.67 & 0.56 & 0.50 & (9) \\
\hline$q_{\text {in }}\left(\mathbf{k W} / \mathbf{m}^{2}\right)$ & 61.0 & 60.3 & 56.4 & 51.0 & 47.7 & (12) \\
\hline $\mathrm{Bi}$ & 0.0022 & 0.0022 & 0.0022 & 0.0022 & 0.0021 & (13) \\
\hline
\end{tabular}


